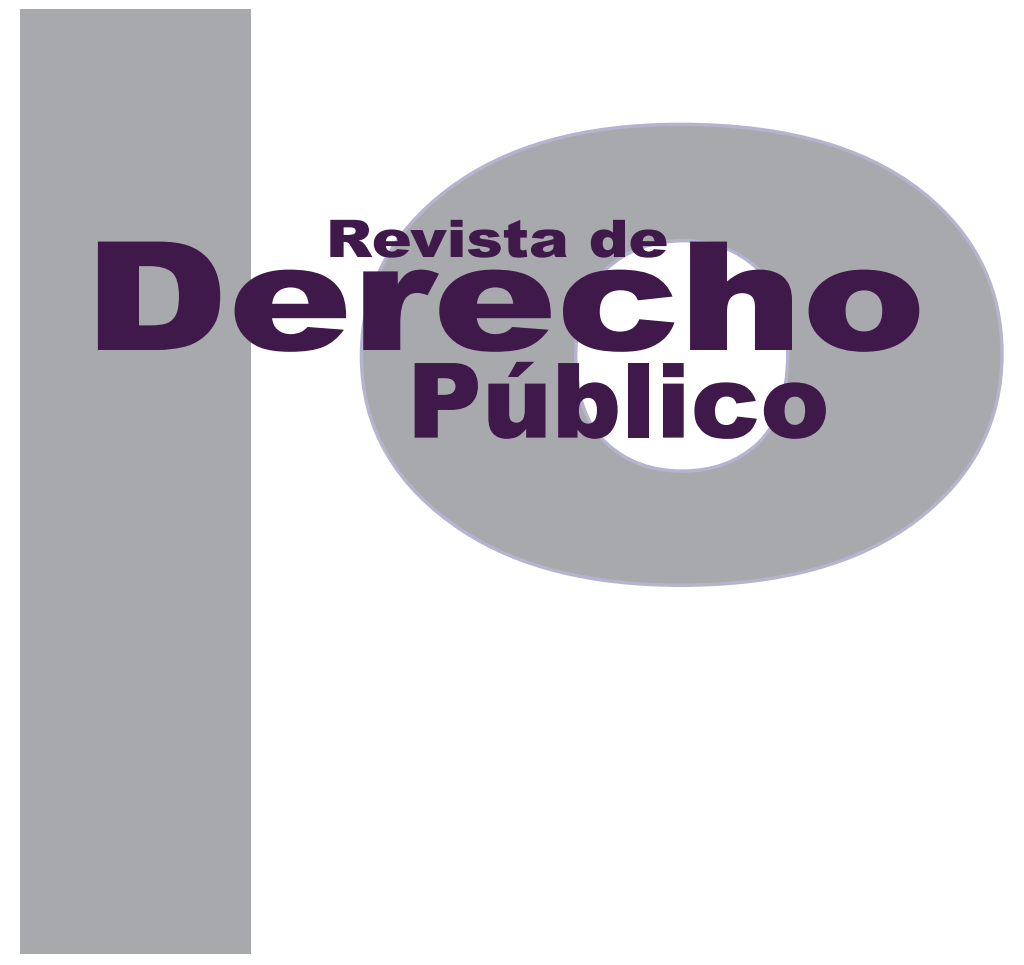

\title{
ESTADO DEL ARTE DE LA VIOLENCIA INTRAFAMILIAR EN COLOMBIA: ESTUDIOS SOCIO-JURÍDICOS
}

\author{
MARÍA ISABEL NiÑo CONTRERAS
}

Artículo de reflexión

DOI: http://dx.doi.org/10.15425/redepub.33.2014.24

Universidad de los Andes

Facultad de Derecho

Revista de Derecho Público N. ${ }^{\circ} 33$

Julio - Diciembre de 2014. ISSN 1909-7778 


\section{Estado del arte de la violencia intrafamiliar en Colombia: estudios socio-jurídicos Resumen}

La violencia intrafamiliar (VIF) constituye una problemática compleja y vigente en la sociedad colombiana. Según el último informe del Instituto de Medicina Legal y Ciencias Forenses, en el año 2013 se presentaron 68.230 casos de viF, de los cuales el $77,58 \%$ fue contra mujeres y $22,42 \%$ contra hombres. En el marco de esta realidad, distintos sectores académicos han fijado su interés en el análisis de la implementación, consecuencias sociales y recepción de las normas contra la VIF. Teniendo en cuenta esto, el objetivo del presente trabajo es dar cuenta del estado del arte de las investigaciones socio-jurídicas realizadas sobre la vIF en Colombia. La metodología utilizada para esta revisión literaria fue el análisis de fuentes bibliográficas de tipo secundario.

Palabras clave: violencia intrafamiliar, violencia doméstica, violencia de género, estado del arte, investigaciones sociojurídicas, Ley 294 de 1996, Ley 575 de 2000, Ley 1257 de 2008.

\section{The state of the art of legal and social research on domestic violence in Colombia}

\section{Abstract}

Domestic violence is a complex issue nowadays in Colombian society. According to the latest report from the Institute of Legal Medicine and Forensic Sciences, during 2013, 68.230 cases of domestic violence took place. $77.58 \%$ was against women and $22.42 \%$ against men. In the context of this reality, academics have focused their interest in the analysis of the implementation, social consequences and the reception of rules against domestic violence. Taking into account this, the objective of this paper is to report the state of the art of legal and social research on domestic violence in Colombia. The methodology used for this literature review was to analyze secondary references.

Keywords: domestic violence, state of the art, legal and social research, law 294 of 1996, law 575 of 2000 , law 1257.

\section{Estado da arte da violência intrafamiliar na Colômbia: estudos sócio-jurídicos}

\section{Resumo:}

A violência intrafamiliar (VIF) constitui uma problemática complexa e vigente na sociedade colombiana. Segundo o último informe do Instituto de Medicina Legal e Ciências Forenses, no ano 2013 foram apresentados 68.230 casos de viF, dos quais $77,58 \%$ foram contra mulheres e $22,42 \%$ contra homens. No marco desta realidade, distintos setores acadêmicos têm manifestado seu interesse na análise da implementação, consequências sociais e recepção das normas contra a VIF. Levando isto em consideração, o objetivo do presente trabalho é dar conta do estado da arte das investigações sócio-jurídicas realizadas sobre a vif na Colômbia. A metodologia utilizada para esta revisão literária foi a análise de fontes bibliográficas de tipo secundário.

Palavras-chave: violência intrafamiliar, violência doméstica, violência de gênero, estado da arte, investigações sóciojurídicas, Lei 294 de 1996, Lei 575 de 2000, Lei 1257 de 2008. 


\title{
Estado del arte de la violencia intrafamiliar en Colombia: estudios socio-jurídicos*
}

\author{
María Isabel Niño Contreras**
}

\section{SUMARIO}

Introducción - I. TEMÁTICAS COMUNES Y CENTRALES EN LA LITERATURA SOCIO-JURÍDICA SOBRE LA VIOLENCIA INTRAFAMILIAR - A. Conciliación - B. Comisarías de familia - C. Capacitación y sensibilización en derechos humanos a los funcionarios y funcionarias que tratan esta problemática - D. Respuesta frente a la viF desde un diseño institucional - 1. Medidas de protección - 2. Penalización de la VIF - 3. Implementación - 3.1. Sector laboral - 3.2. Sector educación y comunicación - 3.3. Sector salud - E. Reflexiones multidisciplinares frente a la VIF - 1. El planteamiento del problema sociocultural de la VIF en Colombia - 2. La protección por la cual se aboga en las investigaciones se hace desde un aspecto familiar o a nivel individual - 3. La revictimización es un fenómeno presente en las mujeres afectadas por la VIF - II. CONCLUSIONES - A. Falta de comunicación entre los investigadores - B. Temáticas que no se han abordado con frecuencia - Referencias.

\footnotetext{
* Cómo citar este artículo: Niño Contreras, M. I. (Diciembre, 2014). Estado del arte de la violencia intrafamiliar en Colombia: estudios socio jurídicos. Revista de Derecho Público, 33. Universidad de los Andes (Colombia).
}

** Abogada de la Universidad de los Andes y estudiante de la Maestría de Derecho de la misma institución. Actualmente es asistente de investigación de la Facultad de Derecho de dicha Universidad. Correo: mi.nino2234@uniandes.edu.co 
Introducción

La violencia intrafamiliar (en adelante VIF), constituye una problemática compleja y vigente en la sociedad colombiana. Según el último informe del Instituto de Medicina Legal y Ciencias Forenses, en el año 2013 se presentaron 68.230 casos de VIF, de los cuales el 77,58\% fue contra mujeres y $22,42 \%$ contra hombres. El primer puesto dentro la vif lo ocupa la violencia de pareja seguida de la violencia entre otros familiares; en tercer lugar la violencia contra niños, niñas y adolescentes; y en último lugar la violencia hacia personas mayores. Las mujeres son las víctimas más frecuentes, salvo en la violencia contra personas mayores donde los hombres ocupan el primer lugar (Instituto de Medicina Legal y Ciencias Forenses, 2013).

En el marco de esta dramática realidad se han adoptado diversas medidas legales con el fin de contrarrestarla. La primera ley promulgada con el objeto de prevenir, remediar y sancionar la VIF fue la 294 en 1996. Dicha normatividad tenía como propósito desarrollar el artículo 42 inciso $5^{1}$ de la Constitución Política y cumplir las obligaciones internacionales derivadas de la Convención de Belem do Pará. ${ }^{2}$ Esta ley constituye un primer reconocimiento a la vIF como un fenómeno independiente de protección legal. La Ley 575 de 2000, en aras de descongestionar los juzgados de familia, otorgó competencia a

1 "Cualquier forma de violencia en la familia se considera destructiva de su armonía y unidad, y será sancionada conforme a la ley”.

2 Los artículos 1, 2, 7 y 8 de esta Convención se relacionan con VIF y con las obligaciones internacionales que adoptaron los Estados al suscribirla. las comisarías de familia para que conocieran sobre estos hechos violentos y tomaran las medidas tendientes a la protección de las víctimas. Adicionalmente, implementó la conciliación en equidad con la finalidad de no llegar a la judicialización del hecho violento y dispuso otras medidas de protección a la víctima. El delito de VIF ha sido modificado varias veces. En este momento, gracias a la Ley 1542 de 2012, este tipo penal no es querellable ni desistible y no requiere de conciliación para ejercer la acción penal.

La Ley 1257 de 2008 dota a las mujeres de medidas más comprensivas y completas frente a cualquier acto de violencia en su contra, incluyendo los que transcurren y se dan desde la familia. Esta ley tiene como finalidad la adopción de medidas que garanticen a las mujeres el derecho a vivir libres de violencia en relación con sus derechos a la salud, educación, trabajo, acceso a la justicia, entre otros. En virtud de esta normatividad, determinadas entidades estatales tienen la responsabilidad de adoptar medidas de prevención, atención, protección y sanción contra la violencia frente a las mujeres. Así mismo, dicha ley integra una perspectiva de género y entiende la violencia contra las mujeres como una violación de derechos humanos que no es producto del azar, ni un hecho de la esfera privada, sino que está íntimamente vinculada con relaciones desiguales de poder entre hombres y mujeres, establecidas y aceptadas por la sociedad.

Dada la importancia de esta temática, el objetivo del presente trabajo es dar cuenta del estado del arte de las investigaciones socio-jurídicas 
realizadas sobre la vif en Colombia. Dicho análisis tendrá como enfoque las principales discusiones, exigencias y preocupaciones de la academia frente a la VIF. Es relevante precisar que se entiende por estudios socio-jurídicos todas las investigaciones relacionadas con la implementación, consecuencias sociales y recepción de las diferentes normas contra la VIF. Así mismo, comprenderá los estudios de raza, género, etnia y otras variables que se cruzan en la realidad frente a la VIF.

La metodología utilizada para esta revisión literaria fue el análisis de fuentes bibliográficas de tipo secundario. Principalmente se consultaron los catálogos públicos de las bibliotecas de varias universidades, entre estas, la Javeriana de Bogotá, el Externado, los Andes, la Nacional de Bogotá, el Rosario, la de Antioquia y la del Valle. Se hizo una lista de los posibles libros y tesis pertinentes a la investigación y a medida que se accedía a la mayoría de ellos se escogían cuáles clasificaban como estudios socio-jurídicos.

Otra fuente importante fue Internet, pues ahí se encontraron documentos relevantes que provenían de entidades del Estado y de organizaciones privadas. Entre estas herramientas se destacan: buscadores como Google, páginas web de entidades del Estado como la Defensoría del Pueblo, la Alta Consejería Presidencial y Medicina Legal, y páginas web de organismos privados como la Corporación Sisma Mujer.

La búsqueda en estos catálogos públicos de las bibliotecas antes mencionadas y en Internet se realizó a través de las siguientes frases:
Primera. Lo relacionado con la implementación de la normatividad: implementación de la Ley 1257 de 2008, implementación de la Ley 294 de 1996, implementación de la Ley 575 del 2000.

Segunda. Términos como violencia intrafamiliar, violencia doméstica, violencia de género, violencia contra la mujer, maltrato intrafamiliar.

Tercera. Todo documento relacionado con las leyes contra la VIF: Ley 1257 de 2008, Ley 575 de 2000, Ley 294 de 1996.

Cuarta. Análisis socio-jurídico de VIF.

Quinta. Comisarías de familia.

En esta revisión literaria se encontraron 33 documentos clasificados de la siguiente forma: 5 libros, 15 monografías de grado, 10 investigaciones de entidades estatales y privadas y 3 artículos de revista. Para mayor detalle sobre estos estudios remitirse a la bibliografía del presente documento.

También resulta importante destacar que durante la realización de este estado del arte se hallaron temáticas comunes y centrales en todos los trabajos académicos, descritas así:

- Implementación de la conciliación como mecanismo para enfrentar la VIF, teniendo en cuenta la naturaleza de este tipo de violencia, los actores que intervienen y los derechos que vulnera.

- Competencia en el conocimiento de la VIF a cargo de las comisarías de familia. 
- Capacitación y sensibilización en derechos humanos a los funcionarios y funcionarias que tratan la viF.

- Respuesta frente a la VIF desde un diseño institucional. Esto comprende un análisis ante la posición que debe asumir el Estado, la formulación de las medidas de protección, el debate frente a la penalización o no de la VIF, y lo referente a la implementación de la normatividad contra la vif en sectores específicos como el laboral, salud, educación y comunicaciones.

- Reflexiones multidisciplinares frente a la VIF. Lo anterior teniendo en cuenta la petición por un abordaje integral ante dicha problemática, la revictimización de las mujeres afectadas por la VIF y la forma como se aboga por la protección de estas, es decir, como sujetos de derechos o como una forma de preservar la familia como unidad.

Partiendo de esas temáticas o asuntos recurrentes, me encargaré de puntualizar los argumentos estructurales en las investigaciones para así construir un panorama sobre los estudios sociojurídicos en la viF.

\section{TEMÁTICAS COMUNES Y CENTRALES EN LA LITERATURA SOCIO-JURÍDICA SOBRE LA VIOLENCIA INTRAFAMILIAR}

\section{A. Conciliación}

Debe hacerse la salvedad que las investigaciones objeto de esta revisión literaria, relacionadas con el debate de la conciliación, datan desde el año 2000 hasta el año 2011, esto es, antes de la promulgación de la Ley 1542 de 2012 que elimina el carácter de querellable y desisitible del delito de viF. De este modo, durante el tiempo en que dichos estudios fueron elaborados, la conciliación constituía un requisito de procedibilidad en el ámbito penal y una práctica común dentro de las comisarías y juzgados de familia. Así, pese a la reforma legal, resulta importante la revisión de esta temática pues no fue un asunto pacífico dentro de las investigaciones, y puede ser útil al momento de analizar la implementación de la Ley 1542 de 2012.

Ahora bien, para empezar es preciso conceptualizar la conciliación como un mecanismo alternativo de solución de conflictos, en el cual se identifican intereses divergentes entre las partes y se negocia con estas un acuerdo (artículo 64 Ley 446 de 1998). Conforme al artículo 3 de la Ley 640 de 2001, esta herramienta dentro de nuestro sistema jurídico puede darse de forma extraprocesal, es decir, antes de iniciar un proceso, o en el curso de uno, como modo de solucionar el asunto. La conciliación en materia de VIF está presente en dos escenarios: el primero son las comisarías y juzgados de familia a donde la víctima acude con el objeto de darle solución a su problema y los funcionarios adoptan esta herramienta como forma de enfrentar dicha situación. ${ }^{3}$ Cabe recordar que en estos casos la conciliación no es requisito de procedi-

3 El artículo 1, parágrafo 1 de la Ley 575 de 2000 establece: "No obstante la competencia anterior podrá acudirse al Juez de Paz y al Conciliador en Equidad, con el fin de obtener, con su mediación, que cese la violencia, maltrato o agresión o la evite si fuere inminente. En este caso se citará inmediatamente al agresor a una audiencia de conciliación, la cual deberá celebrarse en el menor tiempo posible" [cursivas añadidas]. 
bilidad para acudir a la jurisdicción. El segundo escenario son las fiscalías y juzgados penales, en los cuales las víctimas denuncian el hecho violento teniendo la obligación de acudir a una conciliación con su agresor para poder ejercer la acción penal. ${ }^{4}$

Qué hacer con este punto en los asuntos de VIF no ha sido un debate pacífico. Por una parte hay quienes apuntan que la conciliación desconoce el desequilibrio de poder existente entre el agresor y la víctima, donde esta última está supeditada a la intimidación, la fuerza y el miedo a una posible retaliación de su agresor. Por otro lado, existen quienes señalan a este mecanismo como la herramienta idónea para manejar esta problemática en atención a intereses como la unidad familiar, la congestión judicial, la cultura de convivencia ciudadana, entre otras razones. A continuación presentaré este debate reseñando los correspondientes argumentos de cada parte.

El texto base que reúne los principales argumentos contra la conciliación, y que a la vez utilizan un número considerable de autores que tocan el tema, ${ }^{5}$ es el de Julieta Lemaitre Ripoll,

4 Dado el carácter de querellable que ostentaba el delito de VIF, la conciliación era un requisito de procedibilidad para ejercer la acción penal. Lo anterior conforme al artículo 522 del Código de Procedimiento Penal colombiano.

5 Pineda Duque, J. A. y Otero Peña, L. (Febrero, 2004). Género, violencia intrafamiliar e intervención pública en Colombia, Revista de Estudios Sociales, (17); Estrada Jaramillo, L. M. (2010). Acciones públicas para la sensibilización, prevención y sanción de formas de violencia y discriminación contra las mujeres a partir de la Ley 1257 del 2008. (Monografía de grado), Universidad de Antioquia, Medellín; Defensoría del pueblo. (2008). Promoción y monitoreo de los derechos sexuales y reproductivos de mujeres víctimas de desplazamiento forzado con énfasis en violencias intrafamiliar y sexual. Disponible en: http://www. defensoria.org.co/red/anexos/pdf/02/ninez_08.pdf; Gaona Rangel, G. C. (2002). Consecuencias jurídicas y sociales de la ley de violencia intrafamiliar en nuestra sociedad. (Monografía de grado). Universidad Nacional, Bogotá. titulado Justicia Injusta: una crítica feminista a la conciliación en la violencia conyugal. Los argumentos que se comentan en el texto de Lemaitre (2002) son:

Primero. La conciliación en la violencia conyugal, tal y como está diseñada, no es un mecanismo efectivo ni justo para las víctimas. Se pone de presente que el mayor obstáculo a la implementación de las leyes de VIF es la existencia de la conciliación forzosa. Así, la conciliación, entendida como un mecanismo de resolución de conflictos que busca un acuerdo entre las partes, en que ambas logren satisfacer sus pretensiones, no es la herramienta apta para hacerle frente a la VIF. Al ser la VIF una violación de derechos humanos, se ha afirmado que no es susceptible de conciliación (mera negociación) pues ordena una solución en justicia.

Segundo. Otro problema relativo a este mecanismo de solución de conflictos es que no tiene en cuenta la multicausalidad de la vIF, pues esta entraña factores económicos, dependencia afectiva, expectativas asociadas a los papeles de género, presiones familiares, etc., que determinan la forma como se presenta este tipo de violencia. Así mismo, la conciliación desconoce el desequilibrio de poder existente entre el agresor y la víctima, donde esta última está supeditada a la intimidación, la fuerza y el miedo a una posible retaliación de su agresor.

Tercero. No se realiza una graduación de acuerdo con la gravedad del hecho pues existen situaciones que ameritan protección y no conciliación. De este modo, la obligatoriedad de la con- 
ciliación desconoce la gravedad de las ofensas y los problemas de intimidación, y resulta siendo una afectación a los derechos humanos.

De la mano con lo anterior, en el texto se reitera que si la conciliación cambia su enfoque a uno más sensible, es decir, uno que reconozca y busque equilibrar las diferencias de poder entre el agresor y la víctima -abandonando ese ideal de igualdad entre ambas-, y estipula de forma clara en qué circunstancias, dada la gravedad del asunto, no procede, puede constituirse en una herramienta eficiente para la VIF. Se deja claro que la conciliación no debe proceder en los casos graves, inclusive cuando exista voluntad de conciliar pues hay un interés público de que se haga justicia. Existen criterios diferentes para calificar la gravedad de la violencia, como por ejemplo los reseñados por Esmeralda Ruiz en su texto La conciliación en violencia intrafamiliar:

(1) la reiteración de la conducta; (2) que la conducta afecte la dignidad, la voluntad, la capacidad de autodeterminación y libertad de la víctima o agredido; (3) que la conducta infunda pánico o terror en la víctima o agredido/a (amenazas, angustia, humillación); (4) realizar la conducta en presencia de otros/otras miembros del grupo familiar, en particular menores de edad; (5) que se pueda afectar el desarrollo integral de miembros menores de edad pertenecientes al grupo familiar; (6) que logre impedir a la víctima o agredido/a el ejercicio de su derecho de locomoción; (8) que cause lesiones físicas (conductas brutales) (2001, p. 7).

Así, la calificación de la violencia debe basarse no solo en las lesiones personales, sino tam- bién en las posibles afectaciones a la dignidad, el grado de miedo y los sentimientos de la víctima. También es de vital importancia, a criterio de Lemaitre (2002), que la conciliación se lleve a cabo sin coacción, se entienda como un procedimiento que toma tiempo y no pretenda una resolución inmediata del conflicto sino una forma de recomponer la situación.

Cuarto. En cuanto al contenido de los acuerdos conciliatorios es preciso que mejore y se indique qué sucede en caso de incumplimiento y la forma como se realizará su vigilancia y seguimiento. De la mano de esto, es conveniente crear mecanismos efectivos para sancionar el incumplimiento. Si el mecanismo de conciliación sigue tal cual como está, se convertirá en un escenario para la arbitrariedad, la consolidación del poder patriarcal y la injusticia.

Otras investigaciones también han expresado su desacuerdo frente a la conciliación esgrimiendo diferentes argumentos:

Por una parte, se afirma que el hecho de que la VIF sea conciliable hace que la vocación de protección de la ley quede solo en palabras y sea descalificada. Así mismo, se reconoce de forma alarmante que Colombia es de los pocos países en Latinoamérica que contempla la conciliación como un trámite en la violencia hacia la mujer (Castillo, 2008).

También se argumenta que la conciliación no es una herramienta apta para la solución de esta problemática, pues abre la posibilidad a la reincidencia en el acto violento dado que no está 
acompañada de un seguimiento psicológico-familiar (Peña, 2011).

Otro tema que se enmarca dentro de la conciliación, como también lo apunta Lemaitre en su texto Justicia Injusta: una crítica feminista a la conciliación en la violencia conyugal (2002), es el referente al acuerdo conciliatorio. Frente a este punto Lemaitre afirma que, al no comprender plazos ni consecuencias en caso de incumplimiento ni la forma en la cual se le hará una vigilancia o seguimiento, carece de valor y eficacia.

Así mismo, Monroy y Sarmiento (2000) señalan en su investigación que las normas de derecho procesal penal que rigen la conciliación son excesivamente permisivas, generando que las partes abusen de estas sin que medie un ánimo real de acuerdo. De este modo, según dichos autores deben imponerse sanciones más severas para las partes que incumplan los acuerdos conciliatorios. Advierten además que la multa prevista en el ordenamiento civil en caso de incumplimiento puede ser equiparable en el caso del delito de vif. Inclusive, al vulnerarse bienes jurídicos tutelados por el Estado, señalan que la aplicación de estas multas debe ser más exigente.

Adicionalmente, en esta investigación se realizó una serie de propuestas con el objeto de mejorar el acuerdo conciliatorio (Monroy y Sarmiento, 2000):

Primera. Una vez realizado el acuerdo conciliatorio debe procederse a seguir a las partes del conflicto con el fin de establecer si cumplen o no el acuerdo.

Segunda. Los funcionarios judiciales deben fijar un comité con el objetivo de que, a través de charlas y exámenes, evalúen el comportamiento de las partes comprometidas dentro de la problemática de VIF.

Tercera. Debe hacerse una divulgación de la Ley 294 de 1996 pues un gran porcentaje de las personas desconocen los propósitos y los procedimientos de esta normatividad.

Cuarta. Según lo acordado en la audiencia de conciliación y luego de la evaluación a cargo del comité, se dispondrá la suspensión del proceso penal por el término de sesenta días.

Contrario a todo lo expuesto anteriormente y personificando la otra cara del debate, existe otra postura que argumenta que la conciliación es el mecanismo idóneo para hacerle frente a este problema. Así, se propone que el Estado debe fortalecer los mecanismos alternativos de solución de conflictos con el ánimo de generar una cultura de convivencia ciudadana y una auténtica democracia (Limas, 2000).

\section{B. Comisarías de familia}

La Ley 575 de 2000 radicó en cabeza de las comisarías de familia la competencia sobre asuntos de VIF, esto es, el conocimiento del hecho violento y la toma de medidas de protección inmediata sobre la víctima con el fin de que cese la violencia o se evite si fuese inminente. Un nú- 
mero considerable de investigaciones han centrado sus estudios en la atención, el enfoque, la competencia y otros aspectos relevantes de estos entes administrativos.

Una inquietud constante en las investigaciones revisadas son las reformas de las que ha sido objeto la Ley 294 de 1996, pues, a criterio de algunos, dichos cambios legislativos han desnaturalizado el espíritu restaurador y protector que tiene la ley frente a las víctimas. La Ley 575 de 2000, por ejemplo, basándose en la congestión de los despachos judiciales reubica la competencia de las instancias judiciales en las instancias administrativas, es decir, las comisarías de familia, perjudicando de este modo los intereses de las víctimas de VIF (Defensoría del Pueblo, 2008; Hurtado y Rico, 1999). Así, para un sector de la academia no resulta aceptable la asignación de competencia a las comisarías, dada la complejidad y la gravedad del tema. Un problema que se deriva de este cambio es el hecho de que las comisarías de familia dependan de la disponibilidad presupuestal de cada municipio, haciendo en ocasiones difícil el acceso a estos procesos, ante la inexistencia de esta entidad en algunas zonas del país (Estrada, 2010).

Por otra parte, la función que han desempeñado las comisarías de familia ha sido merecedora de duros reclamos. Por ejemplo, el informe presentado por la Procuraduría General de la Nación, Comisarías de familia. Línea de base nacional, muestra los resultados del examen que les fue realizado en el 2011 respecto a su organización, estructura, calidad de la atención y garantía del restablecimiento de derechos. Aquí se comprobó que, pese a la existencia física de las comisarías, su labor se ha visto obstaculizada por la falta de conectividad vial, la no presencia permanente de los comisarios y comisarias, la carencia de un equipo interdisciplinar de trabajo, la deficiencia en el sistema de transporte para funcionarios y usuarios y la sobrecarga laboral. En dicho informe se pone de presente que los comisarios no están capacitados en temas jurídicos. Se comenta además que dichos funcionarios no hacen parte de la carrera administrativa, luego su labor se convierte en un cargo político, desconociendo la naturaleza del trabajo. Otro inconveniente es la poca presencia física institucional para apoyar la labor de las comisarías. Tales argumentos, descritos en el informe, son también expuestos por Vásquez, Alarcón y Amarís (2008).

También se señala en dicho informe que la infraestructura se encuentra en un estado crítico. De las comisarías existentes solo 79 tienen una estructura física óptima, 243 aceptable, 708 deficiente y 41 crítica. Hay un significativo atraso en el desarrollo del objetivo de estas instituciones. Lo anterior, según el informe, demuestra que el Estado no ha reconocido que las violencias contra la mujer y la familia son un asunto de derechos humanos y salud pública, con un alto costo económico y social (Procuraduría General de la Nación, 2011).

Siguiendo lo expuesto, otra de las principales críticas se basa en que la atención brindada por las comisarías a la problemática de la vif es insuficiente. Pese a que no se denuncien ni la mitad de los casos que ocurren, existen dificul- 
tades para seguir y acompañar los hechos violentos denunciados. El proceso de seguimiento después de que la comisaría de familia interviene no es el adecuado. De la mano de lo anterior, dicha deficiencia se enmarca dentro de la congestión de las comisarías, pues el número de casos registrados sobrepasa la capacidad de respuesta de estas entidades (Castillo, 2008).

Así mismo, la ineficiencia en las comisarías se explica a través del abordaje que estas adoptan al momento de tratar esta problemática. Según la investigación realizada por un grupo de estudiantes de la Pontificia Universidad Javeriana de Bogotá para optar al título de psicólogas, las comisarías de familia comprenden el tema desde una óptica más legal que social o psicológica (Carrillo, León y Mayorga, 2003). Llaman la atención sobre el asunto de que dichos entes administrativos no traten a las mujeres maltratadas desde una perspectiva de género, es decir, desde un enfoque que reconozca las diferencias de poder y subordinación entre el agresor y la víctima, sino desde una situación problemática entre pares. Un ejemplo presentado en dicha investigación es el relacionado con la conciliación, momento en que los funcionarios adoptan una estrategia de neutralidad equiparando la posición de las partes y, por consiguiente, negando la intimidación y subordinación existente en este tipo de relaciones.

Pese a lo expuesto previamente, las expectativas de algunas mujeres víctimas de vif que acuden a las comisarías, según opiniones recogidas por dicha investigación, son determinantes para afirmar que el punto de partida de las comisa- rías es bueno en la medida que funcionan como espacios donde las escuchan y les brindan apoyo a su problema. No obstante, observan la falta de tiempo en las citas y la poca difusión que existe de la información sobre la vif y sobre los derechos y las estrategias legales con las que cuentan las mujeres víctimas a partir de las fuentes legales (Carrillo et al., 2003).

Otra preocupación identificada en esta revisión literaria es la relacionada con los registros de muerte violenta de mujeres a causa de la VIF en las comisarías, pues estos son insuficientes y vagos. Así, se advierte la necesidad de implementar definiciones respecto a la detección y registros de estos casos y protocolos de atención similares en las diferentes instancias del Estado, como por ejemplo la Fiscalía General de la Nación (Castillo, 2008).

\section{Capacitación y sensibilización en derechos humanos a los funcionarios y funcionarias que tratan esta problemática}

Es preciso que las personas que atienden asuntos de VIF adopten, al momento de abordar esta problemática, conductas que no lesionen la víctima ni hagan más gravosa su situación, debido a la vulneración de derechos humanos y dignidad humana que entraña este tipo de violencia. ${ }^{6}$ Debe tenerse en cuenta que al ser funcionarios de uno de los escenarios a los cuales acuden

6 En el preámbulo de la Convención de Belem do Para se afirma "que la violencia contra la mujer constituye una violación de los derechos humanos y las libertades fundamentales y limita total o parcialmente a la mujer el reconocimiento, goce y ejercicio de tales derechos y libertades." 
las víctimas a pedir ayuda, es necesario que estos manejen conocimientos y conductas especiales relacionadas con la dignidad humana y la dimensión del problema, como por ejemplo, ser conscientes de que la violencia contra la mujer es una manifestación de las relaciones de poder históricamente desiguales entre mujeres y hombres. ${ }^{7}$ Algunos textos estudiados advierten que la carencia de sensibilización en el manejo de estos casos agrava la problemática de la viF.

En esta revisión literaria se identificó como una queja común, el hecho de que una fuente de discriminación y reproche a las víctimas sean los funcionarios y funcionarias que desconocen la complejidad de la violencia, y afirman cosas tales como "si se queda con él es porque le gusta que le peguen". Frente a este asunto se señala que denunciar el hecho violento no es fácil, pues requiere un proceso largo y reflexivo, de modo que los procedimientos legales y administrativos deben ser vistos por los funcionarios de manera integral, de modo que se permita "descifrar e interpretar el entramado emocional que supone la ruptura de una relación de pareja en la que se presentan situaciones de violencia" (Castillo, 2008, p. 30). Dos obstáculos a la implementación de la normatividad contra la VIF, apuntados en el estudio de estos textos, son el

7 El artículo 8 de la Convención de Belem do Para señala que los Estados Partes se obligarán a adoptar de forma progresiva programas que fomenten "la educación y capacitación del personal en la administración de justicia, policial y demás funcionarios encargados de la aplicación de la ley, así como del personal a cuyo cargo esté la aplicación de las políticas de prevención, sanción y eliminación de la violencia contra la mujer." Así mismo, en el preámbulo de dicha Convención se pone de presente que "la violencia contra la mujer es una ofensa a la dignidad humana y una manifestación de las relaciones de poder históricamente desiguales entre mujeres y hombres." desconocimiento de estas normas por parte de los funcionarios y su falta de sensibilidad y capacidad para enfrentar estas situaciones (Defensoría del Pueblo, 2008), teniendo de presente que "la violencia contra la mujer constituye una violación de los derechos humanos y las libertades fundamentales y limita total o parcialmente a la mujer el reconocimiento, goce y ejercicio de tales derechos y libertades" (Convención de Belem do Para, 1996).

Una de las críticas centrales frente a esta falta de sensibilización consiste en cuestionar la comprensión de los funcionarios respecto a la familia como organización social al momento de establecer soluciones y medidas de protección a la víctima. En consecuencia es común escucharles poner de presente que esta es una organización social que debe estar cohesionada, luego cualquier medida que atente contra su unidad la consideran inadecuada, desprotegiendo en muchas ocasiones a la víctima. Puede pensarse como ejemplo el que un comisario se abstenga de ordenar al agresor el desalojo de la casa que comparte con la víctima (Literal a) art 5, Ley 294/96) en atención a este ideal de unidad familiar (Ospina, 2003).

Otro argumento interesante respecto a la actuación de los funcionarios señala que cuando los familiares de las mujeres que mueren a causa de VIF han buscado ayuda en esas instituciones, estos no reportan el caso por miedo a afectar su estabilidad laboral o a ser considerados indirectamente responsables en la prevención de dicha muerte (Castillo, 2008). 
También surgen propuestas respecto a la formación de los funcionarios, a la necesidad de que el conciliador en equidad y demás funcionarios competentes cuenten con el apoyo de un o una profesional de las ciencias sociales que maneje esta problemática, o reciban con anterioridad una capacitación para el manejo de la dimensión humana del conflicto (Lemaitre, 2002). Así, se advierte que de la misma forma como se creó a través de una ley un procedimiento especial que atendiera la viF, es imperativa la dotación de un personal idóneo y suficiente que labore con los funcionarios, y de un trabajo interdisciplinario donde se tomen decisiones adecuadas que respondan a las verdaderas necesidades de las víctimas (Bohórquez y Corredor, 1999).

\section{Respuesta frente a la VIF desde un diseño institucional}

Un punto central en las investigaciones consiste en cuestionar la actitud o la forma como el Estado debe afrontar la viF. Se afirma que, al tener la familia un estatus de protección e importancia social tanto a nivel nacional como internacional, el Estado debe propender por su adecuada defensa (Peña, 2011). Frente a este asunto, la principal crítica radica en que para poner fin a la VIF se requiere más que la acción coactiva de una ley, dado que una de las formas más eficaces de proteger a los miembros de una familia es replanteando y reformando las políticas sociales y económicas del Estado. Lo anterior, en el entendido de que una parte importante del eje causal de la violencia doméstica está relacionada con lo socioeconómico (Ospina, 2003). Así mismo, se pone de presente que la inter- vención del Estado no puede estar limitada a la promulgación de cierta normatividad contra la violencia. Resulta necesario acompañar estas medidas con estrategias educativas, de sensibilización y propuestas interdisciplinares, dejando como última instancia el derecho penal (Limas, 2000).

Frente a este punto, señala Estrada (2010) que la Ley 1257 ocupa un lugar relegado dentro de las políticas del Estado, a tal punto que no se encuentra incorporada en el Plan Nacional de Desarrollo. Las políticas de sensibilización y prevención tienen un carácter coyuntural y no representan compromisos nacionales de largo plazo. También recuerda esta investigación que dichos planes no cuentan con una adecuada asignación de recursos, ni con herramientas de evaluación y monitoreo que posibiliten medir el avance del país frente a una vida libre de violencia hacia las mujeres. La capacidad de atención y el número de servicios implementados son reducidos, y muchas veces dependen de cooperación internacional. Lo anterior, a criterio de Estrada (2010), se traduce en una relación de subordinación de los gobiernos, quienes se aprovechan de la temporalidad del financiamiento para no darle alcance a las políticas y programas, y para no determinar compromisos de largo plazo.

En concordancia con lo anterior, el Estado debe tener una actitud interventora y no al margen de la situación, al punto que debe asumir la responsabilidad por toda acción u omisión frente al tema de violencia contra la mujer y no limitarse a la promulgación de normas (Corporación Sisma Mujer, 2006). 


\section{Medidas de protección}

La Ley 294 de 1996 y la Ley 1257 de 2008 establecen medidas en cabeza de los comisarios y jueces de familia, tendientes a la protección de las víctimas de VIF, siempre que hallen amenazas para la vida, la integridad física o la salud de cualquiera de los miembros de la familia. Estas medidas, de acuerdo con el artículo 5 de la Ley 294/96, consisten en:

a) Ordenar al agresor el desalojo de la casa de habitación que comparte con la víctima.

b) Ordenar al agresor abstenerse de penetrar en cualquier lugar donde se encuentre la víctima.

c) Prohibir al agresor esconder o trasladar de la residencia a los niños, niñas y personas discapacitadas en situación de indefensión y miembros del grupo familiar.

d) Obligar al agresor a acudir, a costa suya, a un tratamiento reeducativo y terapéutico en una institución pública o privada que ofrezca tales servicios.

e) Ordenar al agresor, si fuere necesario, el pago de los gastos de orientación y asesoría jurídica, médica, psicológica y psíquica que requiera la víctima.

f) Ordenar, por parte de la autoridad competente, una protección temporal especial a la víctima por parte de las autoridades de policía, tanto en su domicilio como en su lugar de trabajo si lo tuviere, cuando la violencia o maltrato revista gravedad y se tema su repetición.

g) Ordenar a la autoridad de policía el acompañamiento a esta (víctima) para su reingreso al lugar de domicilio.

h) Decidir provisionalmente el régimen de visitas, la guarda y custodia de los hijos e hijas si los hubiere.

i) Suspender al agresor la tenencia, porte y uso de armas.

j) Decidir provisionalmente quién tendrá a su cargo las pensiones alimentarias.

k) Decidir provisionalmente el uso y disfrute de la vivienda familiar.

I) Prohibir al agresor la realización de cualquier acto de enajenación o gravamen de bienes de su propiedad sujetos a registro, si tuviere sociedad conyugal o patrimonial vigente.

m) Ordenar al agresor la devolución inmediata de los objetos de uso personal, documentos de identidad y cualquier otro documento $u$ objeto de propiedad o custodia de la víctima.

n) Cualquiera otra medida necesaria para el cumplimiento de los objetivos de la presente ley.

Existe preocupación en la academia frente a la ineficacia e inaplicabilidad de las medidas de protección en la realidad. Cuando las agresio- 
nes son permanentes, por ejemplo, las medidas de protección no son efectivas. De este modo, cuando la medida consiste en alejar al agresor del domicilio común, pero permitirle regresar una vez se le pasa el estado agresivo, no se está cumpliendo la finalidad para la cual ha sido prevista dicha medida: proteger la integridad de la víctima y evitar nuevas agresiones. En este sentido, en algunas investigaciones de esta revisión literaria se apunta la importancia de buscar mecanismos efectivos para la real operatividad de dichas disposiciones (Castillo, 2008).

Se puntualiza en una de las investigaciones estudiadas la importancia de analizar los límites y alcances que tiene la medida de desalojo en los casos de VIF, dada la relevancia de la propiedad en la sociedad. Aquí se establece que la medida de desalojo es la más severa y es utilizada en los casos más graves, pues limita el uso y goce del bien al agresor (propietario) en busca de darle una función social al bien inmueble. Esta medida procura proteger a la familia como núcleo fundamental de la sociedad a través del uso de la propiedad, acorde con el interés de la comunidad (Rodríguez, 2005).

Frente a la medida de protección de ordenar al agresor abstenerse de penetrar en cualquier lugar donde se encuentre la víctima es pertinente preguntarse lo siguiente: ¿de qué medios dispone el comisario de familia o los jueces civiles o promiscuos municipales para controlar que el agresor realmente se abstenga de penetrar en los lugares donde la mujer se encuentra? Lo anterior implicaría un trabajo conjunto con la policía nacional, cuerpo que tiene el deber de apoyar a las comisarías de familia para que las medidas sean efectivas en la práctica (Rodríguez, 2005). Para lograr esto es importante un trabajo de sensibilización al interior de esta institución, con el fin de cambiar los prejuicios e imaginarios acerca de la violencia contra la mujer. Una propuesta planteada es que el Estado continúe fortaleciendo a las mujeres a través de programas formativos y de atención psicológica y terapéutica, para que sean ellas quienes tomen la decisión de no dejar entrar a sus agresores a sus espacios de vivienda y habitación (Corporación Sisma Mujer, 2009).

Ahora bien, en cuanto a los tratamientos reeducativos se apunta que el Estado debe ofrecer las condiciones indispensables para que estos cumplan con el objetivo para el cual han sido previstos. En la práctica, conforme a lo encontrado en esta revisión literaria, esta medida de protección no es efectiva. Por ejemplo, solo se acude a dos sesiones de las diez dispuestas por el funcionario competente (Corporación Sisma Mujer, 2009). Se señala también que la intervención de los funcionarios se limita a la amonestación a los agresores para que no continúen maltratando, y en casos muy aislados a conminarlos a que asistan a terapia psicológica, situación que queda a voluntad de las partes (Bohórquez y Corredor, 1999). Debe destacarse que son pocas las instituciones tanto públicas como privadas que ofrecen los tratamientos reeducativos y terapéuticos que impone la ley al agresor como medida de protección. Además, en muchos casos los agresores no cuentan con los recursos para acceder a estos tratamientos (Gaona, 2002). Se advierte la conveniencia de 
articular esta medida teniendo de presente el factor laboral, esto es, que se les autoricen permisos a los agresores y víctimas para atender este tipo de tratamientos (Corporación Sisma Mujer, 2009).

\section{Penalización de la VIF}

Existe preocupación frente a la penalización o no de la VIF. Hay quienes afirman que la penalización de la conducta no es la herramienta adecuada para afrontar este problema, y que sería mejor que se agotara con anterioridad un proceso reeducativo, diferente a la privación de la libertad, respecto al agresor (Gaona, 2002).

En esta misma línea, se señala en una investigación que la penalización de la viF deslegitima el objeto protector del derecho penal, pues resulta más lesivo para el bien jurídico de la familia ya que en la práctica se generan rencillas familiares y más violencia y sentimientos de venganza que no apuntan a la resolución del problema. La penalización con privación de la libertad, según estas investigaciones, es una medida incoherente y contradictoria de cara a la normatividad constitucional y a la realidad social, puesto que afecta la cohesión y unidad de la familia (Monroy y Sarmiento, 2000). Otra investigación considera que el hecho de que se criminalice la VIF demuestra que el legislador deja todo en manos del derecho penal y se libra de toda responsabilidad al momento de proponer soluciones y respuestas efectivas (Limas, 2000).

Un argumento distinto contra la penalización de la VIF está relacionado con la idea de observar cómo, a pesar de que existan reglas no solo de carácter constitucional, sino ahora también de carácter penal, ha sido muy difícil implementar una medida que realmente reduzca el problema. Aun cuando la vif se penalizó desde el 2004, en la práctica común tanto funcionarios públicos como los ciudadanos todavía ven con extrañeza la penalización de actividades privadas como son las relaciones familiares (Gómez, 2004).

\section{Implementación}

Las investigaciones sobre la implementación de las normas contra la VIF muestran un panorama desalentador, pues en ellas se apunta que las entidades a las cuales se les delegó la tarea de aplicar y apropiarse de toda la normatividad no han contestado de la forma esperada o prevista. En especial respecto a la Ley 1257 de 2008 es evidente que la incapacidad de las autoridades competentes para definir políticas y diseñar programas en desarrollo de lo establecido, se debe en su mayoría a que dicha normatividad no determinó tiempos específicos, ni entidad alguna que vigile su correcta implementación y cumplimiento (Estrada, 2010).

Cabe anotar que uno de los principales textos consultados es un informe de seguimiento a la implementación de la Ley 1257 de 2008, preparado por la Mesa por el derecho de las mujeres a una vida libre de violencia, en el $2012 .^{8}$ En este se señala que cuando se intentó pregun-

8 Pese a que este informe se haya presentado en el 2012 los correspondientes derechos de petición se realizaron en 2011. 
tar por el cumplimiento de la mencionada ley, los entes encargados no ofrecieron la información pertinente para identificar cuáles son los programas y proyectos promovidos y ejecutados desde su expedición, con el objetivo de erradicar la violencia contra las mujeres. De este modo, no fue posible conocer lo que se ha hecho o se piensa hacer en esta materia, dejando más interrogantes que respuestas. En dicho informe se reconoce que en el país se están adelantando acciones en favor de la mujer a nivel municipal, departamental y nacional, sin embargo no existe un organismo coordinador y articulador que posibilite que las políticas a nivel central se expandan al nivel local. También resalta que las entidades consultadas presentaron resultados muy generales de su gestión en cumplimiento de mandatos legales diferentes a la Ley 1257 de 2008, y advierte lo preocupante que resulta ser el enfoque familiar desde el que actúan estos entes, pues comprenden a la mujer exclusivamente desde el ámbito familiar y la anulan como sujeto de derechos.

Específicamente, entidades estatales como la Fiscalía General de la Nación, el Ministerio de Educación, el Instituto Colombiano de Bienestar Familiar, la Policía Nacional y el Ministerio del Interior y de Justicia presentaron informes muy generales y no enfocados en la implementación de la ley. Se limitaron a mencionar las funciones de cada quien y su gestión en relación con el cumplimiento de mandatos legales y constitucionales. Es importante mencionar que algunas entidades nunca respondieron: Ministerio de Protección Social, Departamento Administrativo de Seguridad, entre otros. Por su parte, el balance presentado por la Alta Consejería Presidencial para la Equidad de la Mujer no fue específico respecto a la implementación de la ley, de modo que quedaron muchos aspectos sin un desarrollo suficiente o totalmente ausentes en la investigación.

Otra forma de explicar lo referente a la implementación y la ineficacia de las políticas públicas es teniendo de presente las siguientes causas:

Primera. El Estado no ofrece la cobertura necesaria para la debida ejecución de estos programas, haciendo que el objetivo de la erradicación de la vIF quede solo en el papel (Gómez, 2004).

Segunda. Las medidas establecidas por el Estado presentan dificultades por la escasa consideración que se tiene de los patrones culturales y las identidades de género en el contexto de la VIF. Las familias tienen una organización patriarcal que deforma el rol de las mujeres y las posiciona como sujetos inferiores. Cualquier intervención está limitada no solo por la gran demanda y el modelo de atención adoptado, sino también por los valores e imágenes culturales de las autoridades (Pineda y Otero, 2004).

Tercera. La indiferencia y el silencio de la comunidad ante estas conductas (Gómez, 2005).

Esta insatisfacción respecto a la forma como se ponen en marcha las normas ha sido justificada también desde las expectativas que tienen las mujeres víctimas de vIF frente al aparato legal. En la monografía de grado ¿Y de la satisfacción 
que?: posibilidades de lo jurídico para responder a los pedidos de las mujeres violentadas por su pareja, se recogen opiniones de un grupo de mujeres víctimas y se establece que las mujeres persiguen en la denuncia un espacio donde puedan ser escuchadas respecto a lo que piensan y sienten al interior de la relación. No obstante, se pone de presente la realidad de que las leyes solo pueden interferir en la conducta del agresor y no en los sentimientos y los conflictos a nivel psíquico de la pareja. Adicionalmente, se expone que esta puede ser la razón por la cual las mujeres quedan insatisfechas frente a la respuesta legal dada por el Estado, pues, pese a que se logre un cese de la violencia, las expectativas de las víctimas no encuentran lugar en esta solución (Escobar, 2006).

Por otra parte, la Ley 1257 de 2008 estableció medidas específicas en cada sector. Es preciso describir las falencias apuntadas por las investigaciones en cada ámbito. En este apartado se utiliza de forma primaria el conjunto de documentos desarrollados por la Corporación Sisma Mujer en atención a una consultoría respecto a la implementación de la mencionada ley.

\subsection{Sector laboral}

Respecto a las medidas tendientes a mejorar las oportunidades de empleo con "el ingreso de las mujeres a espacios productivos no tradicionales para ellas", la Corporación Sisma Mujer (2012a) en su informe Consultoría para la implementación de la Ley 1257 de 2008 en el sector laboral, indica que dicha acción afirmativa va encaminada a promover la igualdad en escenarios laborales donde la mujer ha sido históricamente discriminada, y no en generar estabilidad socioeconómica en las mujeres víctimas de la violencia. La norma no explica cuáles son los espacios productivos no tradicionales a los cuales debe acceder la mujer, lo cual genera un vacío que hace difícil la implementación de dicha medida. A su vez, advierte que no se estipula un término para la adopción de esta política, situación que puede dejar indefinida por mucho tiempo esta materia. Para contrarrestar la formulación tan amplia de la política, propone la necesidad de solicitar información al Ministerio de Protección Social sobre las medidas que ha adoptado respecto al tema.

Otro foco de análisis de este informe son los estímulos tributarios para los empleadores que contraten a las mujeres víctimas de violencia comprobada. El beneficio otorgado por la ley consiste en la deducción de la renta del “200\% del valor de los salarios y prestaciones sociales pagados durante el año o período gravable" siempre y cuando medie una relación laboral hasta por un período de tres años. Esta política se ubica en el ámbito de la generación de empleo para la estabilización socioeconómica de las mujeres víctimas de la violencia, y busca que los empleadores creen oportunidades laborales a cambio de beneficios tributarios.

No obstante, el informe en comento señala que, pese a que se estipule claramente el beneficio tributario, las condiciones de acceso no son precisas. Por ejemplo, no se determina cómo se debe comprobar la violencia o si es factible aplicar el beneficio a mujeres ya contratadas o 
es requisito que sean contrataciones nuevas. Lo anterior indica la necesidad de esclarecer las condiciones de acceso, pues de lo contrario puede dar lugar a usos inadecuados en los cuales se conceda el beneficio a empleadores que no generen nuevos trabajos o que soliciten a las mujeres ya contratadas que se declaren víctimas de violencia. Otro problema de la medida en mención señalada en dicho informe, es la poca publicidad o conocimiento que tiene este beneficio tributario entre los empleadores y las mujeres víctimas de la violencia, lo cual genera poco impacto. Para contrarrestar estos obstáculos, se sugiere en el informe la necesidad de darle publicidad a la medida, esclarecer las condiciones para acceder al beneficio, y agrupar y visibilizar la demanda de trabajo por parte de las mujeres víctimas de la violencia.

Así mismo, respecto a las medidas tendientes a mejorar las condiciones de empleo de las mujeres, en el informe se establecen tres focos: “(1) reconocimiento social y económico del trabajo de las mujeres, (2) efectividad de la igualdad salarial -en el cual también participan ARP, empleadores y contratantes- y (3) erradicación de la discriminación y la violencia contra las mujeres en el ámbito laboral" (p. 9). Una crítica que allí se plantea a la aplicación de esta medida, es que las obligaciones están redactadas en términos muy amplios y generales, lo cual puede dificultar su efectividad a condición de "exigir un capital político más grande para que se concreten" (p. 10). Por esto recomienda que se adopten mecanismos y medidas específicas sobre el tema.
Otro aspecto relevante del informe que nos ocupa es el referente a las disposiciones relacionadas con el acoso, concretamente sobre la obligación de "tramitar las quejas de acoso sexual" y de "otras formas de violencia contra la mujer" contempladas en la ley ante las administradoras de riesgos profesionales (ARP), los empleadores o contratantes, las cooperativas de trabajo asociado y las demás organizaciones que tengan un objeto similar. Al Ministerio de Protección Social le corresponde velar por el cumplimiento de esta obligación. Dada la naturaleza de las ARP, esta obligación impuesta por la ley les es nueva, de ahí que en el informe se afirme que esta norma necesita reglamentos para su aplicación, ya que al involucrar la tramitación de quejas es imperativo que se establezcan reglas para su desarrollo que respeten el debido proceso. No obstante, se advierte en este informe que los temas de violencia y acoso contra la mujer no pueden tramitarse mediante procesos administrativos reglados por funcionarios privados, sino que dada la importancia que entrañan estas conductas el problema debe ser abordado por los jueces y propone que dichas competencias de instrucción se transformen en una forma de acompañamiento o protección a las mujeres en procesos de denuncia y en campañas de prevención y promoción de erradicación de violencia.

En concepto de quienes elaboraron el informe, las medidas que se adoptaron en esta ley son sobre todo obligaciones en cabeza de autoridades, con el fin de que se establezcan políticas relacionadas con la generación de oportunidades laborales, el mejoramiento de la calidad en 
las condiciones de trabajo, entre otras. Sin embargo, al ser órdenes que no fijan términos de cumplimiento quedan como actos de voluntad política. Sin embargo, esta generalidad en las normas no es pretexto para que no se adopten políticas concretas y efectivas; tampoco puede ser excusa el que la implementación de estas políticas traiga consigo gastos para el Estado, haciendo difícil o imposible su realización. Se recuerda en este informe que para la jurisprudencia constitucional, cuando el goce efectivo de un derecho constitucional fundamental depende del desarrollo progresivo,

lo mínimo que debe hacer [la autoridad responsable] para proteger la prestación de carácter programático derivada de la dimensión positiva de [un derecho fundamental] en un Estado Social de Derecho y en una democracia participativa, es, precisamente, contar con un programa o con un plan encaminado a asegurar el goce efectivo de sus derechos. Por ello, al considerar un caso al respecto, la Corte señaló que si bien el accionante no tiene derecho a gozar de manera inmediata e individualizada de las prestaciones por él pedidas, sí tiene derecho a que por lo menos exista un plan (sentencia T-760 de 2008).

Otras formas de materializar estas medidas son una mayor publicidad para que sean conocidas por las beneficiarias y el constante seguimiento frente a las autoridades competentes.

\subsection{Sector educación y comunicación}

Respecto a las medidas dispuestas en los sectores de educación y comunicación, el informe de la Corporación Sisma Mujer (2012b): Consultoría para la implementación de la Ley 1257 de 2008 en el sector Educación y Comunicaciones, expone la necesidad de definir con claridad cuáles entidades tienen responsabilidad en la implementación de la ley; cuáles son los recursos disponibles; y a qué entidad le corresponde la asesoría psicológica, los cursos de capacitación y la estabilización en los derechos económicos, sociales y culturales de las mujeres. Adicionalmente, señala la importancia de expedir un Conpes que articule salud, educación, comunicación y cultura en los asuntos de género para hacer realidad el cumplimiento de la Ley 1257 de 2008. También muestra la importancia de consultarles a las mujeres víctimas de la VIF sobre sus expectativas en cada uno de los puntos del articulado de la ley.

\subsection{Sector salud}

Un punto crítico identificado en el informe Consultoría para la implementación de la Ley 1257 de 2008 en el sector Salud (Corporación Sisma Mujer, 2012c) es el relacionado con la financiación, pues algunas medidas contenidas en la ley dejan los gastos a cargo del sistema de salud, sin indicar de forma concreta la fuente de dicha financiación.

Otro inconveniente tiene que ver con las mujeres que no se encuentran vinculadas ni al régimen contributivo ni al subsidiado por su baja capacidad económica, producto de su poca educación y bajos ingresos, y que sufren una situación más fuerte de vulnerabilidad no solo a la violencia, sino a una menor cobertura en salud (no tienen, por ejemplo, acceso a incapacidades). 
Ahora bien, pese a que la mayoría de investigaciones señalan los pocos avances y la baja implementación de las leyes, existe también la postura que insiste en que la normatividad vigente (Ley 1257 de 2008) puede analizarse como un progreso significativo respecto a los derechos de las mujeres, la intervención del Estado y los nuevos mecanismos de protección para víctimas de vif. Ramírez (2010) pone de presente:

a. En relación con los derechos de las mujeres víctimas:

- Derecho a contar con orientación, asesoramiento jurídico y asistencia técnica legal con vocación especializada, inmediata y gratuita;

- Derecho a reservar su identidad;

- Derecho a ser informadas sobre métodos anticonceptivos y derechos sexuales y reproductivos;

- Derecho a decidir voluntariamente si quieren confrontar al agresor en los espacios de atención y en los procedimientos administrativos y judiciales. Las mujeres víctimas no pueden ser obligadas a asistir a una conciliación y su no asistencia en ningún caso puede dar lugar a la terminación de los procedimientos iniciados.

b. En relación con las obligaciones del Estado: definir la violencia contra la mujer como violación a los derechos humanos trae como consecuencia la obligación en cabeza del Estado de implementar medidas de sensibilización, pre- vención, protección, atención y sanciones contra este tipo de violencia.

c. Medidas de sensibilización y prevención: promueven el avance en la transformación cultural libre de discriminación hacia las mujeres. Así mismo, la ley contiene un catálogo de deberes para la familia y la sociedad en relación con el trato a la mujer. La norma establece medidas correspondientes al ámbito laboral, salud, educación y comunicación.

d. En relación con la protección de mujeres víctimas de vif la ley dispuso nuevas medidas.

e. En relación con la atención a mujeres víctimas de violencias: la ley prevé alternativas para las mujeres que desean salir de su casa hasta que se resuelva la situación. Esto es, servicios de habitación, alimentación en las instituciones prestadoras del servicio de salud y en hoteles, en favor de la víctima, sus hijos e hijas. Adicional se les asignará un subsidio monetario para cubrir dichos gastos.

f. Respecto a las sanciones a los victimarios se señalan dos avances:

(1) Creación del delito de acoso sexual;

(2) Incremento de penas por delitos que se cometan contra la mujer por el hecho de serlo.

\section{E. Reflexiones multidisciplinares frente a la VIF}

Una preocupación latente en las investigaciones analizadas es la forma como se estudia y solu- 
ciona la VIF. Dada la complejidad y la naturaleza del asunto, la mayoría de estos textos apuntan a que los planteamientos y propuestas que se realizan deben hacerse desde una óptica integral. Esta perspectiva no radica únicamente en la formulación de políticas públicas sino también en su implementación. Hay quienes afirman que para solucionar este problema no bastan las medidas legales sino que es pertinente la intervención de otras disciplinas. Seguido a esto, consideran que es necesario implementar la ley desde una perspectiva de género, es decir, reconociendo las diferencias, realidades y problemas que giran en torno a los roles de la mujer y el hombre dentro de la sociedad. Advierten que las leyes sin procedimientos de formación íntegros y concisos, que no den cuenta de la realidad que afecta a las mujeres, son insuficientes, e inclusive pueden agravar la situación que se pretende solucionar (Ramírez, 2010).

Como ya se mencionó, los documentos estudiados hacen énfasis en la idea de que para erradicar la VIF deben adoptarse no solo medidas jurídicas, sino también otras de tipo económico, social, cultural y de alcance internacional (Gómez, 2005). La solución de esta problemática no provendrá de los textos legales, sino de una pedagogía de los derechos humanos que aumente los niveles de cultura política (Limas, 2000). Adicionalmente, señalan que cualquier solución que se proponga debe tener un carácter multidisciplinario para que la respuesta sea integral, pues el derecho por sí solo no resuelve el problema (Estrada, 2010). También advierten que replantear las políticas públicas que regulan este tema y reforzar las medidas de preven- ción y concientización deben ir acompañados de educación e inversión estatal, además de un seguimiento especializado de la familia en general, que impida la reproducción del ciclo de la VIF (Peña, 2011).

Pese a que se reconoce la aparición de la legislación como un primer paso en la erradicación de la violencia al interior de las familias, se hace la observación de que esta por sí sola no resuelve el problema, pues esta violencia responde a valores ancestrales muy arraigados en la sociedad. En consecuencia, proponen el desarrollo de estrategias de empoderamiento de las mujeres para que se sientan miembros con plenos derechos en la comunidad, con capacidad y acceso para tomar cualquier decisión (Consejo Superior de la Judicatura, 2000a).

Por otra parte, existen investigaciones que abordan el análisis de la VIF desde perspectivas diferentes al derecho, esto es: el género, las condiciones socioeconómicas, la religión y cuestiones psicológicas.

Así, por ejemplo, la vif puede abordarse desde la perspectiva del lenguaje, desplazando las normas por un análisis discursivo de la situación. Quienes así opinan hacen un análisis crítico del lenguaje utilizado por las mujeres maltratadas, en el que afirman que pese a la existencia de un sistema institucionalizado para la resolución de conflictos y, específicamente, uno para la denuncia de VIF, siguen autonombrándose de cierta forma y permaneciendo en una cárcel discursiva de la cual no son conscientes; las mismas mujeres desarrollan un discurso que las sitúa 
en un lugar de fragilidad e incapacidad que sirve para atribuirse a sí mismas la culpa por los hechos de violencia. Aquí se evidencia la necesidad de reformular los trámites de denuncia para que las mujeres sean conscientes de que el maltrato no es justificable y, sobre todo, no es objeto de autoincriminación (Godoy, 2006).

La VIF ha sido abordada también desde una perspectiva religiosa, en la cual se busca encontrar la causa de esta forma de violencia en el quebrantamiento de la alianza conyugal. Este tipo de investigaciones justifican la conexidad de la violencia con el mantenimiento de la unidad familiar, pilar de la sociedad (Vela, 2006).

Desde una aproximación de género a la viF se ha argumentado que el desempleo y la pobreza son elementos relevantes en la relación entre la consolidación de la masculinidad y la violencia perpetrada por hombres. Lo anterior hace énfasis en la idea de que tales circunstancias incentivan a los hombres a hacer uso del "derecho" de ejercer la violencia contra las mujeres cuando estas no cumplen normas implícitas de lo que de ellas se espera (Pineda y Otero, 2004). También desde esta perspectiva se han analizado los principales espacios de socialización como la familia, la escuela y los medios de comunicación, y su influencia en la construcción de las identidades masculinas, haciendo referencia a la división sexual del trabajo. En este tipo de investigaciones se vincula la idea de la construcción de la masculinidad y la forma en la que se expresa el imaginario de ser hombre con episodios de violencia y de control sobre el cuerpo femenino (Consejo Superior de la Judicatura, 2000b).

\section{El planteamiento del problema socio- cultural de la vif en Colombia}

Una de las razones por las cuales la violencia dentro de la familia sigue siendo un problema vigente en la sociedad es la concepción y legitimación social que de ella se tiene. Dentro de los textos estudiados se encontró una crítica común respecto a la legitimidad de la viF en la sociedad colombiana, como consecuencia de patrones culturales, psicológicos, históricos o religiosos.

Se afirma que la VIF ha sido históricamente legitimada, pues se entiende la familia como un espacio privado que no responde ni preocupa a los intereses públicos o de bienestar general. En Colombia, la legitimación es tal que el uso de la violencia se considera el método propicio para educar a un niño (Peña, 2011).

En el documento de Profamilia, Feminicidio: mujeres que mueren por violencia intrafamiliar en Colombia, su autora, Elizabeth Castillo Vargas (2007) señala que la violencia contra la mujer sigue viéndose como algo natural, a tal punto que puede verse al feminicidio como consecuencia del desinterés institucional, la tolerancia a la violencia hacia las mujeres y la responsabilidad social de quienes crean opinión; pone de presente que el papel de los medios de comunicación es importante en la medida en que pueden ser grandes promotores de los derechos de las víctimas de la VIF; y recuerda que las noticias o los informes acerca de los feminicidios o cualquier maltrato hacia la mujer requieren de un lenguaje claro y sin estereotipos o prejuicios que refuercen la legitimación y aceptación de la vio- 
lencia en algunas situaciones. Un ejemplo que puede representar la anterior idea es el relativo a cómo los medios de comunicación al momento de presentar una noticia sobre maltrato sexual a la mujer, justifican de cierta forma esta violencia en atención a criterios como la ropa o el lugar donde se encontraba la víctima. Este tipo de justificaciones entraña prejuicios respecto a la legitimidad que tiene el hombre para violentar el cuerpo de la mujer siempre que esta vista o se comporte de determinada manera. Lo anterior desconoce los derechos de las víctimas y contribuye a la aceptación de esta violencia dentro de la sociedad (Castillo, 2007).

Otro ejemplo de esta legitimización social es el hecho de que los funcionarios judiciales acepten la conciliación, pues consideran que la vif no es lo suficientemente lesiva o no merece el mismo trato que otras conductas punibles (Monroy y Sarmiento, 2000).

\section{La protección por la cual se aboga en las investigaciones se hace desde un aspecto familiar $o$ a nivel individual}

Un punto común en todas las investigaciones es el considerar la viF como un problema serio que necesita solución. Sin embargo, en materia de protección hay dos visiones en tensión respecto a qué bienes jurídicos están siendo objeto de lesión: la familia o la integridad y dignidad de la mujer. La primera entiende el problema como una afectación a la unidad familiar. En esta línea, el Estado debe actuar contra la VIF pues se considera violatoria de la protección del núcleo familiar constitucionalmente amparado. Aquí es preciso rescatar los valores familiares, la estabilidad de la pareja y el cuidado de los hijos como una forma de salvaguardar la sociedad (Limas, 2000). Así, las leyes sobre vif, aunque pueden revestirse de una especial protección a la mujer, deben privilegiar a la familia por encima de los derechos individuales. Resulta claro para estas investigaciones cómo los desarrollos legislativos han decidido proteger a la mujer dentro del hogar más que a la mujer como sujeto de derechos (Villa, 2006).

La segunda postura aboga por la protección contra la VIF desde una perspectiva individualista, al considerar a la mujer como sujeto de derechos y de amparo en sí misma. El Estado y las leyes deben proteger a la mujer víctima pues los actos violentos atentan contra su integridad y dignidad como persona (Villa, 2006). Dicha forma de abogar por la protección contra la vIF se basa en el reconocimiento de la dignidad humana. Al respecto, en las investigaciones analizadas se señala que en la jurisprudencia de la Corte Constitucional se ha determinado que la dignidad humana es un principio superior y creador del Estado social de derecho. Así mismo, filósofos y teóricos importantes han dimensionado la dignidad de una persona como su capacidad de autodeterminación y de ser un fin en sí mismo y no un instrumento para cierto fin, y hacen especial énfasis en la idea de que la VIF constituye un ultraje a la dignidad de la mujer, pues la reduce a ser un instrumento al servicio de intereses egoístas.

En este sentido, se afirma que la VIF hacia la mujer debe contrarrestarse desde los estrados 
judiciales a través de la tutela de la dignidad humana, y que dada la importancia que detentan los principios en el ordenamiento jurídico, la Ley 1257 de 2008 debió establecer como su pilar y fundamento el principio de la dignidad humana (Estrada, 2010).

\section{La revictimización es un fenómeno presente en las mujeres afectadas por la VIF}

La revictimización es un fenómeno que consiste en hacer víctima a una persona que ya lo es, por una circunstancia diferente. En los casos de VIF las mujeres maltratadas son consideradas víctimas de esta situación; no obstante, sobre algunas de ellas recae una segunda victimización al encontrarse en otra circunstancia que lesiona sus derechos y por lo tanto agrava su situación. Las investigaciones estudiadas señalan dos tipos de revictimización: una, la que sufren las mujeres víctimas del desplazamiento; otra, la que se deriva de las normas que castigan y tratan la VIF.

El informe de la Defensoría del Pueblo: Promoción y monitoreo de los derechos sexuales y reproductivos de mujeres víctimas de desplazamiento forzado con énfasis en violencias intrafamiliar y sexual, muestra la dramática situación de la revictimización de las mujeres víctimas de la VIF y a su vez víctimas del desplazamiento. Allí se anota que el $44,3 \%$ de las mujeres desplazadas y casadas o en unión libre han sido víctimas de violencia por parte de su esposo o compañero (Defensoría del Pueblo, 2008).
Otra forma de revictimización de las mujeres proviene de las normas y de los funcionarios y sus prejuicios al momento de abordar estos temas. La falta de sensibilización y capacitación en estos asuntos muchas veces degenera en un nuevo perjuicio o daño sobre los derechos de las mujeres y en una protección deficiente, pues las víctimas se sienten vulneradas nuevamente al acudir a las entidades que deben protegerlas y ver que la solución es inadecuada, más gravosa o que muchas veces la violencia resulta legitimada (Castillo, 2008; Gaona, 2002).

\section{CONCLUSIONES}

A manera de conclusiones propongo lo siguiente:

\section{A. Falta de comunicación entre los investigadores}

Una observación relevante en esta revisión literaria es la relativa a que los investigadores no se leen entre sí, ni usan los hallazgos de otras investigaciones al momento de plantear sus análisis. La anterior observación tiene como consecuencia que dentro del panorama de investigaciones se repitan temáticas, se llegue a similares conclusiones, y que los debates planteados no se desarrollen, pues no encuentran asidero en otros estudios o escenarios. En últimas, los investigadores se mueven circularmente y no analizan temas nuevos ni profundizan en los ya existentes, simplemente se limitan a estudiar sin pensar en la construcción de nuevos debates y soluciones. Esta dinámica hace que de cierta forma se pierda el esfuerzo intelectual de quienes investigan sobre el tema. 


\section{B. Temáticas que no se han abordado con frecuencia}

A través del presente estado del arte se pudo detectar los principales vacíos al momento de investigar y abordar la problemática de vif desde una óptica socio-jurídica:

- El no abordaje del problema desde un análisis comparado. Las investigaciones son muy locales, esto es, no consultan fuentes ni textos internacionales que puedan enriquecer el debate nacional.

- La ausencia de una dialéctica entre los investigadores hace que no se construyan ni se agrupen los principales argumentos o debates sobre la VIF. Sería útil consolidar todas las teorías, hipótesis e ideas que giran en torno a esta problemática, en publicaciones y escenarios donde sea más fácil la exploración y búsqueda. La mayoría en este momento se encuentran en bibliotecas universitarias por corresponder a trabajos de grado.

- Las investigaciones analizadas no profundizaron en la forma como la legislación protege o no a las víctimas de los distintos tipos de violencia, por ejemplo la sexual. Hacen un mapeo general pero no específico del tipo de protección que merece cada forma de violencia.

- No se abordaron los móviles ni la coyuntura política que influyó en la promulgación de la normatividad contra la VIF. Solo se analizaron los procesos legislativos que rodearon cada ley con el objeto de constatar el discurso político que entraña este tipo de normas respecto a la mujer o la violencia.

- Siendo la legislación sobre VIF un desarrollo de instrumentos internacionales faltó analizar con más detenimiento esta relación, principalmente lo correspondiente a la Convención de Belem do Para.

- Pese a que se hace mención especial a la conciliación, poco se analizó la figura de la mediación a la que se refiere el capítulo III del Libro VI (justicia restaurativa, artículos 523 y ss.), del Código de Procedimiento Penal, aplicable para el tipo penal de VIF.

\section{Referencias}

Bohórquez Joya, N. y Corredor Rojas, A. (1999). Análisis descriptivo de los efectos generados por las sentencias sobre violencia intrafamiliar de los juzgados de familia de Santafé de Bogotá, D. C. 1999. (Tesis de maestría). Universidad Nacional, Bogotá, Colombia.

Carrillo Corzo, M., León Rondón, J. y Mayorga Puyo, M. (2003). Representaciones sobre el abordaje de la violencia intrafamiliar en dos comisarías de familia de la ciudad de Bogotá. (Tesis para optar el título de psicóloga). Pontificia Universidad Javeriana, Bogotá, Colombia.

Castillo Vargas, E. (2007). Feminicidio: mujeres que mueren por violencia intrafamiliar en Colombia: estudio de casos en cinco ciudades del país. Bogotá: Profamilia. 
Consejo Superior de la Judicatura, Sala Administrativa, Escuela Judicial Rodrigo Lara Bonilla. (2000a). Violencia intrafamiliar IV (reflexiones sobre violencia de pareja y relaciones de género). Bogotá: Autores.

Consejo Superior de la Judicatura, Sala Administrativa, Escuela Judicial Rodrigo Lara Bonilla. (2000b). Violencia intrafamiliar V (masculinidades). Bogotá: Autores.

Corporación Sisma Mujer. (2006). La sagrada violencia intrafamiliar en Colombia. Recuperado el 11 de julio de 2012, de sisma mujer: http://www.sismamujer.org/

Corporación Sisma Mujer. (2009). Consultoría para la implementación de la Ley 1257 de 2008 en el sector Justicia. Recuperado el 13 de junio de 2012, de sisma mujer: http:// www.sismamujer.org/

Corporación Sisma Mujer. (2012a). Consultoría para la implementación de la Ley 1257 de 2008 en el sector laboral. Recuperado el 11 de junio de 2012 de sisma mujer: http:// www.sismamujer.org/

Corporación Sisma Mujer. (2012b). Consultoría para la implementación de la Ley 1257 de 2008 en el sector Educación y Comunicaciones. Recuperado el 12 de junio de 2012 de sisma mujer: http://www.sismamujer.org/

Corporación Sisma Mujer. (2012c). Consultoría para la implementación de la Ley 1257 de 2008 en el sector Salud. Recuperado el 13 de junio de 2012 de sisma mujer: http:// www.sismamujer.org/

Defensoría del Pueblo. (Junio de 2008). Promoción y monitoreo de los derechos sexuales y reproductivos de mujeres víctimas de desplazamiento forzado con énfasis en violencias intrafamiliar y sexual. Obtenido de Acnur: http://www.acnur.org/biblioteca/pdf/6683. pdf?view=1

Escobar Ortiz, D. C. (2006). ¿Y de la satisfacción que?: posibilidades de lo jurídico para responder a los pedidos de las mujeres violentadas por su pareja. (Tesis de grado para optar el título de psicóloga). Universidad de Antioquia, Medellín, Colombia.

Estrada Jaramillo, L. M. (2010). Acciones públicas para la sensibilización, prevención y sanción de formas de violencia y discriminación contra las mujeres a partir de la Ley 1257 del 2008. (Tesis de maestría en Derecho). Universidad de Antioquia, Medellín, Colombia.

Gaona Rangel, G. C. (2002). Consecuencias jurídicas y sociales de la ley de violencia intrafamiliar en nuestra sociedad. (Tesis de grado para obtener el título de Especializado en Instituciones Jurídico Procesales). Universidad Nacional, Bogotá, Colombia.

Godoy Casasbuenas, M. P. (2006). El denuncio por violencia conyugal o el encarcelamiento discursivo de la mujer: análisis crítico de ocho testimonios de maltrato doméstico. (Tesis de grado para obtener el título de Profesional en Lenguajes y Estudios Socioculturales). Universidad de los Andes, Bogotá, Colombia. 
Gómez Luna, O. (2005). Las políticas públicas (Haz Paz) y el maltrato intrafamiliar en Colón, Génova, Nariño. (Tesis de grado para optar el título de Especialista en Derecho de Familia). Universidad Nacional, Bogotá, Colombia.

Gómez Pombo, E. (2004). Violencia intrafamiliar: ¿límites a su penalización? (Tesis de grado para obtener el título de Abogado). Universidad de los Andes, Bogotá, Colombia.

Hurtado, M. y Rico, A. (1999). Naturaleza del conflicto en el Área de Atención de Familia. Bogotá: Consejo Superior de la Judicatura, Universidad Javeriana, Grupo Política, Género y Familia.

Instituto Nacional de Medicina Legal y Ciencias Forenses. (2013). Informe FORENSIS: datos oficiales sobre la violencia en Colombia en el 2013. Recuperado de medicinalegal: http://www.medicinalegal.gov.co/documents/10180/188820/FORENSIS+2013+7+violencia+intrafamiliar.pdf/dd93eb8c-4f9a41f0-96d7-4970c3c4ec74

Lemaitre Ripoll, J. (2002). Justicia Injusta: una crítica feminista a la conciliación en la violencia conyugal. Revista Derecho Privado, (27), 73-98.

Limas Suárez, A. R. (2000). Deslegitimación del sistema penal frente a la penalización de la violencia intrafamiliar en Colombia, un análisis a partir de un estudio regional municipios de Sora, Cucaita y Samacá, departamento de Boyacá. (Tesis de grado para obtener el título de Especialista en Instituciones Jurídico Pe- nales). Universidad Nacional, Bogotá, Colombia.

Mesa por el derecho de las mujeres a una vida libre de violencia: Ley 1257 de 2008. (2012). Informe de la mesa sobre la implementación de la Ley 1257 y su estado actual de cumplimiento. Obtenido de rednacionaldemujeres: http://www.rednacionaldemujeres.org/images/documents/iinformemesa1257.pdf

Monroy González, I. L. y Sarmiento Jiménez, M. (2000). El incumplimiento de la conciliación en el delito de violencia intrafamiliar. (Tesis de grado). Universidad Nacional, Bogotá, Colombia.

Ospina Vega, M. E. (2003). ¿Las acciones de protección contempladas en la Ley 575 del 2000 son las adecuadas para brindar atención a la violencia intrafamiliar? (Tesis de grado para optar al título de Especialización en Instituciones Jurídico Procesales). Universidad Nacional, Bogotá, Colombia.

Peña Fajardo, H. D. (2011). Violencia intrafamiliar en Colombia: la situación de los niños, niñas y adolescentes. (Tesis de grado para optar al título de Abogado). Universidad de los Andes, Bogotá, Colombia.

Pineda Duque, J. A. y Otero Peña, L. (2004). Género, violencia intrafamiliar e intervención pública en Colombia. Revista de Estudios Sociales, (17), 19-31.

Procuraduría General de la Nación. (2011). Comisarías de familia. Línea de base nacional. 
Obtenido de procuraduría.gov: http://www. procuraduria.gov.co/portal/media/file/Procurando\%206\%20ene\%2012-12.pdf

Ramírez Cardona, C. C. (2010). Ley 1257 de 2008: por el derecho de las mujeres a una vida libre de violencias. Bogotá: Mesa por el derecho de las mujeres a una vida libre de violencia.

Rodríguez Lee, F. (2005). Análisis del desalojo como medida de protección en violencia intrafamiliar. (Tesis de grado para obtener el título de Abogado). Universidad de los Andes, Bogotá, Colombia.

Ruiz, E. (2001). Conciliación en violencia intrafamiliar. Bogotá: Consejería Presidencial para la Política Social.
Vásquez Alfaro, M., Alarcón Palacio, Y. y Amarís Macías, M. (2008). Violencia intrafamiliar: efectividad de la ley en el barrio Las Flores de la ciudad de Barranquilla. Revista de Derecho Universidad del Norte, (29), 178-210.

Vela Vela, Z. (2006). La violencia intrafamiliar y su incidencia en la ruptura de la alianza conyugal. (Tesis de grado para optar al título de Licenciado en Ciencias Religiosas). Pontificia Universidad Javeriana, Bogotá, Colombia.

Villa, M. (2006). Análisis de género en el tratamiento de la violencia intrafamiliar y en la sentencia C-355 de 2006. (Tesis de grado para obtener el título de Abogada). Universidad de los Andes, Bogotá, Colombia. 